\title{
Synthesis and investigation of sulfonated acetone-formaldehyde polycondensate as dispersant for coal-water slurry
}

\author{
Junfeng Zhu*a, Guanghua Zhang ${ }^{b}$, Junguo Lic $^{\mathrm{c}}$, Fang Zhao ${ }^{\mathrm{d}}$, Qianqian $\mathrm{Qu}^{\mathrm{e}}$
}

Key Laboratory of Additives of Chemistry \& Technology for Chemical Industry, Ministry of Education; College of Chemistry and Chemical Engineering, Shaanxi University of Science \& Technology, Xi'an 710021, China

aemail:zjfeng123123@163.com(corresponding author), bemail:zhanggh@sust.edu.cn, cemail:lijunguo@sust.edu.cn, ${ }^{d}$ email: 526822350@qq.com, eemail:6324139430@qq.com

Keywords: sulfonated acetone-formaldehyde(SAF), dispersant, coal-water slurry (CWS), application

\begin{abstract}
According to the literature preparation process, sulfonated acetone - formaldehyde polycondensate (SAF) was prepared with different mole ratio of formaldehyde (F) and acetone (A). Its structure was characterized by IR and TGA. SAF was applied in the Shenhua coal-water slurry (CWS). And the slurryability and stability of the CWS were tested using the viscometer. Wetting performance of SAF dispersant on the surface of coal was studied via video contact angle. The SAF, synthesized with the mole ratio of formaldehyde and acetone at 2.2, performances best in Shenhua coal-water slurry. The SAF is a promising dispersants for Shenhua coal after it was optimized. Under $65 \mathrm{wt} \%$ of the coal concentration and $0.45 \mathrm{wt} \%$ of the dosage of dispersant, the viscosity of CWS is $476 \mathrm{~m} \mathrm{~Pa} \cdot \mathrm{s}$ at the shear rate of $100 \mathrm{~s}^{-1}$, the 7 days separating water ratio is $4.63 \mathrm{v} / \mathrm{v} \%$, and wetting properties of SAF is better than water on the coal surface.
\end{abstract}

\section{Introduction}

The dispersant of coal-water slurry is the key to prepare high quality CWS. Now days, naphthalene additive is mainly coal-water slurry additives on the China's market. Its price rapid rises with increasing of the price of crude oil as raw material [1]. Other additives such as humic acids, lignosulfonate of additives are cheap, but they are less effective. However, efficient additives such as the polyolefin and polycarboxylate are high prices [2-4]. It is significant to develop a new high cost performance additives. Sulfonated acetone - formaldehyde polycondensate (SAF) has a wide range of sources of raw materials and it is affordable and less toxic [5-7]. There has also been a lot of good reported about it as a coal water slurry additive, but it has not been explained clearly the SAF in which degree of polymerization of the polymer (or molecular weight) performance best $[8,9]$. This paper attempts to prepare a series of sulfonated acetone-formaldehyde polycondensate for Shenhua coal-water slurry (SAF), by controlling the process conditions. Then the application properties of SAF were evaluated and the process conditions of SAF were optimized.

\section{Experimental Seation}

Materials and instruments. Acetone, anhydrous sodium sulfite and sodium hydroxide are chemically pure; $37 \%$ formaldehyde and $98 \%$ concentrated sulfuric acid.

VECTOR-22 fourier transform infrared spectroscopy (Bruker Co., Germany) by the $\mathrm{KBr}$ tablet, thermal stability analysis via Q500 thermogravimetric analyzer (TA Co., American), Easydrop video wetting angle meter (Kruss company, Germany), NXS-4C CWS viscometer (CWS Engineering Research Center of Chengdu instrument Factory), XM-4 type of planet grinding machine (Guangdong Foshan Keli ceramics Co.)

Synthesis of sulphonated acetone - formaldehyde condensation. Anhydrous sodium sulfite and water were added to the flask, and they were heated and stirring about $40{ }^{\circ} \mathrm{C}$. Then acetone was

\footnotetext{
${ }^{*}$ Corresponding author. Tel.: +86-029-86168934. E-mail address: zjfeng123123@163.com (J.F. Zhu)
} 
added into the flask until they were completely dissolved. The reaction solution was sulfonated at $55{ }^{\circ} \mathrm{C}$ for $40-60 \mathrm{~min}$. At the end of sulfonation, formaldehyde was slowly dropped into the solution. At the same time of feeding, the solution was slow warmed. The temperature of the reaction mixture was elevated to $85-90{ }^{\circ} \mathrm{C}$ for 3-4 hours. Then, the polycondensate mixture was cooled and adjusted $\mathrm{pH}$ to 7 . The polycondensate synthesized were precipitated by ethanol and dried in the oven.

Preparation and characterization of coal-water slurries. A Shenhua coal that had been pulverized by a dry ball mill was used in this study. The Shenhua coal is not bonding and has low degree of metamorphism. CWS were prepared from coal particles in water using a mechanical mixer for $10 \mathrm{~min}$. The coal solids concentration was fixed at 60 72wt\%.The dosage of dispersant was $0.3 \sim 0.5 \mathrm{wt} \%$ of dry coal (30 wt\% dispersant at the basis of the dry coal).

\section{Results and discussions}

Dispersant performance and stability in the ratio of different materials. As a good performance dispersant, it should have the appropriate molecular weight and molecular weight distribution. It should also have the proper viscosity. During the experiment, under the fixed feeding method, amount of sodium sulfite, reaction temperature and time, a series of polycondensate products were synthesized through changing the mole ratio of formaldehyde and acetone. The results are shown in Tab. 1.

Tab. 1 Reactant ratio on the dispersion properties.

\begin{tabular}{|c|c|c|c|c|}
\hline $\begin{array}{c}\text { Molar ratio of } \\
\mathrm{n}(\mathrm{F}): \mathrm{n}(\mathrm{A})\end{array}$ & Viscosity /mPa·s & Mobility & $\begin{array}{c}\text { Separating water } \\
\text { rates after 7 days \% }\end{array}$ & Hard precipitation \\
\hline 1.8: 1 & 553 & poor & 5.40 & a little \\
$2.0: 1$ & 589 & good & 4.92 & a little \\
$2.2: 1$ & 476 & perfect & 4.63 & no \\
$2.4: 1$ & 483 & good & 4.91 & no \\
$2.6: 1$ & 566 & ordinary & 4.96 & no \\
$2.8: 1$ & 694 & ordinary & 5.16 & a little \\
\hline
\end{tabular}

Note: $\mathrm{n}(\mathrm{F}) \mathrm{n}(\mathrm{A})$ is mole ratio of formaldehyde and acetone
It can be seen from Tab. 1 , when the amount of other reactants and reaction conditions were fixed, with the increase of the amount of formaldehyde, the viscosity of CWS and separating water ratio obtained reduce at the first then increase. The mobility and hard precipitation first rise and then reduce. In total, the of optimized ratio n (F):n (A) is 2.2:1. So the SAF dispersant via optimized ratio of 2.2:1 was used in the latter discussion.

Infrared analysis of SAF. As was shown in Fig. 1, the polycondensate product has hydroxyl stretching vibration at $3440.69 \mathrm{~cm}^{-1}$, the $\mathrm{C}-\mathrm{H}$ stretching vibration on fat family of molecular chains at $2926.52 \mathrm{~cm}^{-1}$, the carbonyl absorption peak at $1602.64 \mathrm{~cm}^{-1}$, S-O stretching vibration at $1178.60 \mathrm{~cm}^{-1}$ and $1044.29 \mathrm{~cm}^{-1}$. It shows the polycondensate product synthesized is an aliphatic high-molecular polymer containing hydrophilic functional groups of sulfonic acid, hydroxyl and carbonyl. It is structured as follows:

$\left(\mathrm{CH}_{3}\right)_{2} \mathrm{C}\left(\mathrm{SO}_{3}{ }^{-}\right)-\mathrm{O}-\left[\mathrm{CH}_{2} \mathrm{CH}_{2} \mathrm{COCH}_{2} \mathrm{CH}_{2} \mathrm{O}\right]_{\mathrm{n}}-\mathrm{C}\left(\mathrm{SO}_{3}{ }^{-}\right) \mathrm{C}\left(\mathrm{CH}_{3}\right)_{2}$

Thermal gravimetric analysis. From Fig. 2, 5\% SAF decomposition is at temperature of $116^{\circ} \mathrm{C}$, and $10 \%$ SAF decomposition is at $158{ }^{\circ} \mathrm{C}$, then rapid decomposition temperature is at $320{ }^{\circ} \mathrm{C}$. It can express the SAF is high temperature resistance, good thermal stability and suitable to use in high temperature environment.

Optimum of dispersant concentration and CWS concentration. When the concentration of coal-water slurry was constant, just the amount of dispersant changing, the viscosity of CWS with 
different concentration dispersant was tested. As depicted in Fig. 3. The optimum dispersant concentration is $0.45 \mathrm{wt} \%$ on the basis of dry coal. In the case of constant concentration dispersant, the concentration of CWS was changed from 63-72 wt\%. From Fig. 4, the viscosity of CWS sharply rises with increasing of the concentration of CWS. It reveals the most appropriate concentration of CWS is $65 \mathrm{wt} \%$.

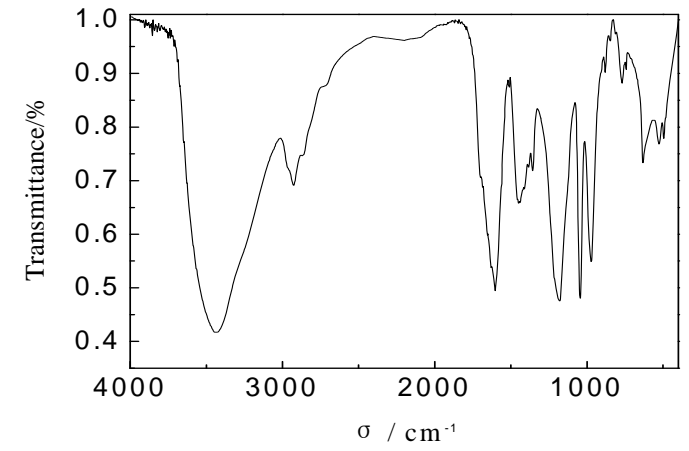

Fig. 1 FTIR spectrogram of SAF

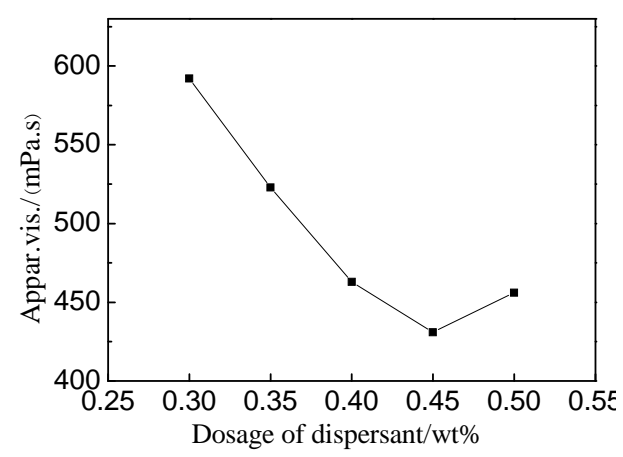

Fig. 3 Effect of dosage of dispersant on the viscosity of CWS

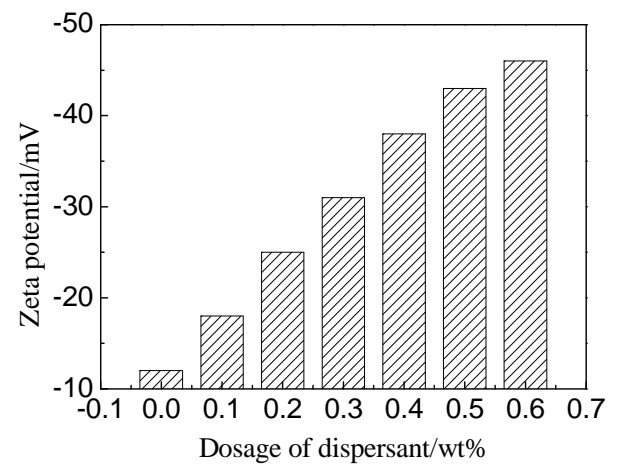

Fig. 5 Zeta potentials of CWS with different dosage of dispersant.

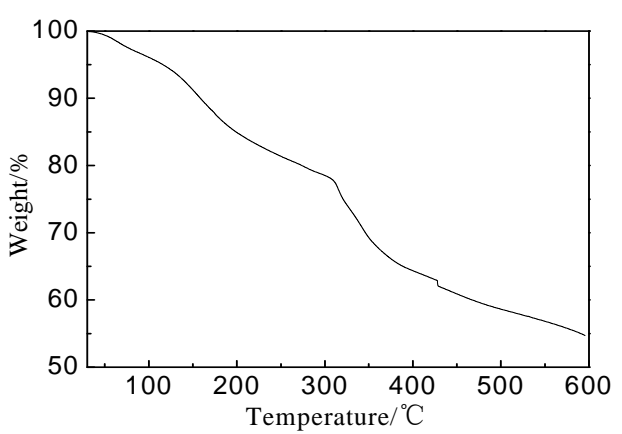

Fig. 2 TGA of SAF

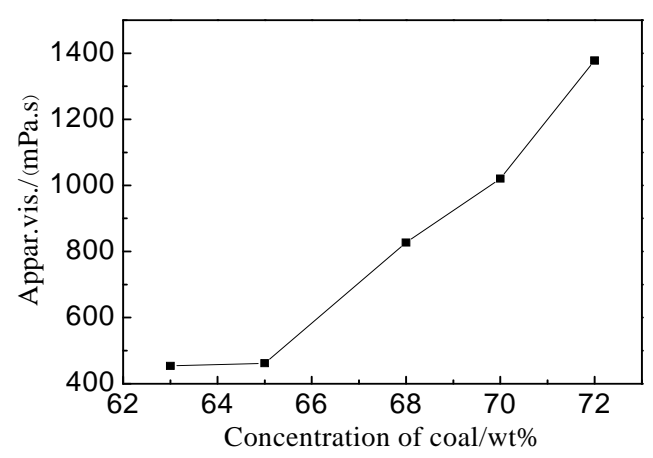

Fig. 4 Effect of coal concentration on the viscosity of CWS

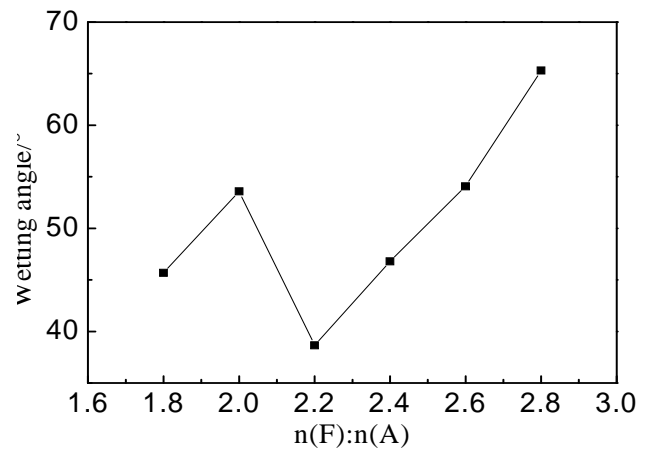

Fig. 6 Wetting angles of dispersants with different ratio of reactants on coal.

Zeta potential. The relationship between Zeta potential and stability of the system shown in Fig. 5. The stability of CWS with Zeta potential of \pm 30 to \pm 40 is general, and the stability of CWS with zeta potential of \pm 40 to \pm 60 is good. As expressed in Fig. 6, all potential showed a negative charge, it indicated that the dispersed particles were negative. Furthermore, the absolute value of Zeta potential gradually increased with the dispersion concentration increases. It illustrated the CWS became stabilized after it was added dispersant. Meanwhile, the sites of action of dispersants and coal surface increase and formed a more stable diffuse double layer at the interface. The potential difference between the continuous phase and the fluid stable layer adhering on the dispersed particles increases, the system increasingly at steady state afterwards.

Dispersants on the coal surface wettability. The dispersant for CWS is also a surfactant, and its dispersion mainly depends on the affinity dispersant and coal. In the other word, if the dispersant can freely spread out on the coal surface. The wetting angle is a measure of the spreading extent. The smaller wetting angle is the better dispersion is. On the contrary, the poorer dispersion is. From Fig.6, when the mole ratio of formaldehyde and acetone is 2.2:1, contact angle of the smallest is up 
to $38.5^{\circ}$. The SAF dispersant synthesized under this condition performance best. It accords with the result of contact angle.

\section{Summary}

The SAF synthesized under the mole ratio of formaldehyde and acetone at 2.2. The SAF performances best in Shenhua coal-water slurry. Under $65 \mathrm{wt} \%$ of the coal concentration and 0.45 $\mathrm{wt} \%$ of the dosage of dispersant, the viscosity of CWS is $476 \mathrm{~m} \mathrm{~Pa} \bullet \mathrm{s}$ at the shear rate of $100 \mathrm{~s}^{-1}$, the 7 days separating water ratio is $4.63 \mathrm{v} / \mathrm{v} \%$. The SAF is a promising dispersants for Shenhua coal after it was optimized.

\section{Acknowledgements}

This work is supported by the Natural Science Foundation of China (No. 21176148), the Scientific Subject Foundation of the Education Department of Shaanxi Provincial Government (No. 11JK0562) and Natural Science Grant of Shaanxi University of science \& technology (No. ZX11-16) .

\section{References}

[1] D.Debadutta, P. Sagarika, K. M. Pramila, N. Malendu, Effect of organized assemblies. part 4. formulation of highly concentrated coal-water slurry using a natural surfactant, Energy Fuels. 22(2008)1865-1872.

[2] J.F. Zhu, G. H. Zhang, Z. Miao and H. Hao, Fabrication and preparation of coal-water slurry dispersant with amphoteric polycarboxylate, Adv. Mater. Res. 335-336 (2011) 1257-1261.

[3] X. Q. Qiu, M. S. Zhou, D.J. Yang, Evaluation of sulphonated acetone-formaldehyde (SAF) used in coal water slurries prepared from different coals, Fuel 86 (2007) 1439-1445.

[4] G. H. Sayeda, F. M. Ghuibab, M. I. Abdoub, E. A. A. Badrb, S. M.Tawfikb, N. A. M. Negmb, Synthesis, surface and thermodynamic parameters of some biodegradable nonionic surfactants derived from tannic acid. Colloids Surf., A: Physicochem. Eng. Aspects, 393(2012) 96-104.

[5] J.F. Zhu, G.H. Zhang, J. G. Li, Preparation of Amphoteric Polyacrylamide Flocculant and Its Application in the Treatment of Tannery Wastewater. J. Appl. Polym. Sci. 120( 2011)518-523.

[6] Z.J. Zhou, X. Li, J. M. Liang, J. Z. Liu, J. H. Zhou, K. Cen, Surface Coating Improves Coal_Water Slurry Formation of Shangwan Coal, Energy Fuels 25(2011)3590-3597

[7] D. Debadutta, P.Sagarika, K. S. Pradipta, P. K. Misra, Effect of Organized Assemblies. Part 5: Study on the Rheology and Stabilization of a Concentrated Coal-Water Slurry Using Saponin of the Acacia concinna Plant. Energy Fuels 23(2009) 3217.

[8] I. Panagiotis, S. Maria, B. Georgios, S. Georgios, Water-Soluble Hydrogen-Bonding Interpolymer Complex Formation between Poly(ethylene glycol) and Poly(acrylic acid) Grafted with Poly (2-acrylamido- 2-methylpropanesulfonic acid). Langmuir 22(2006) 9181-9186.

[9] D. Debadutta, D. Uma, N. Amalendu, K. M. Pramila, Surface Engineering of Low Rank Indian Coals by Starch-Based Additives for the Formulation of Concentrated Coal-Water Slurry. Energy Fuels 24 (2010)1260. 